\title{
Grades, Aspirations, and Postsecondary Education Outcomes
}

\author{
Louis N. Christofides \\ Universities of Cyprus and Guelph \\ Michael Hoy \\ University of Guelph \\ Joniada Milla, Corresponding author \\ University of Guelph and CORE \\ Thanasis Stengos \\ University of Guelph
}

\begin{abstract}
In this paper, we exploit a rich longitudinal data set to explore the forces that, during high school, shape the development of aspirations to attend university and achieve academic success. We then investigate how these aspirations, along with grades and other variables, impact educational outcomes such as going to university and graduating. It turns out that parental expectations and peer factors have direct and indirect effects on educational outcomes through their impact on both grades and aspirations. Policy measures that enlighten parents about the value of education may positively modify educational outcomes.
\end{abstract}

\section{Résumé}

Cet article profite d'une riche base de données longitudinales qui permet d'explorer les influences qui, au cours des études secondaires, poussent les étudiants à aspirer à une formation universitaire et à atteindre ainsi une forme de réussite académique. Nous étudions ensuite comment ces aspirations, les notes obtenues, ainsi que d'autres variables, exercent une influence sur l'éducation, comme les études universitaires et l'obtention d'un diplôme. 
Il appert que les attentes parentales et l'influence des pairs produisent des effets directs et indirects sur les résultats scolaires de par leurs répercussions tant sur les notes obtenues que sur les aspirations des étudiants. Les mesures politiques qui éclairent les parents quant à la valeur de l'éducation pourraient améliorer les résultats universitaires.

\section{Introduction}

The importance of education in general, and postsecondary education (PSE) in particular, for personal growth and fulfillment are well recognized. Moreover, the positive societal externalities that stem from schooling (Lochner \& Moretti, 2004; Milligan, Moretti, \& Oreopoulos, 2004) and the significance of this fabric of knowledge for the process of economic growth are now well accepted (see Hanushek \& Woessman, 2008, pp. 627-632 for a succinct overview on the theoretical and empirical literature). Apart from the many theoretical explorations, a large empirical literature on the determinants of university attendance has emerged. This empirical research focuses on a number of important issues. Studies of the determinants of university attendance link the PSE decisions of children to their cognitive and non-cognitive abilities, their other characteristics, and the characteristics of their family (Day, 2009; Frenette, 2009). Other studies have examined such factors as important gender dimensions (Christofides, Hoy, Li, \& Stengos, 2008; Frenette \& Zeman, 2007; Jacob, 2002) and the significant role of parental education and income (see Finnie \& Mueller, 2008; Johnson \& Rahman, 2005; Knighton \& Mirza, 2002; Zhao, Corak, \& Lipps, 2003, among many others). Apart from the effects of individuals' own characteristics and their parents' characteristics, the empirical literature also provides evidence that friends from school and the neighbourhood influence the behaviour and decision making of individuals, including the decision to drop out of high school (see Foley, Gallipoli, \& Green, 2009), the decision to pursue PSE education, as well as decision making in many other social contexts (workplace environment, smoking, drinking alcohol, taking illegal drugs, committing crimes, and engaging in safe or unsafe sexual practices).

Our paper contributes to the empirical literature that attempts to understand the channels through which various factors influence the educational choices of children. In particular, we focus on the importance of the PSE expectations of students, their parents, and their peers as these influence a child's lifetime education decisions and outcomes. It is well established that parents' educational attainment and, more broadly, their socioeconomic status, have strong effects on children's aspirations and success in educational attainment. ${ }^{1}$ While social inequities no doubt drive these relationships, a careful and focused analysis of the channels through which parental expectations and peer effects influence the paths of children's educational achievements and ultimate aspirations/outcomes can help to inform how, in piecemeal fashion, one may dampen the effects of differential socioeconomic status and promote higher and more equitable PSE attendance outcomes. We take this as our modest goal rather than trying to address and propose means to alter or eliminate the base causes of social inequities. It must be recognized, however, that such macro-sociological effects are important drivers of the phenomenon we study. ${ }^{1}$

A substantial literature, both sociological and economic, has explored the importance of family background and the role of expectations and aspirations for children's educational attainment. This research is reviewed comprehensively by Andres et al. (2007), who 
contribute to that literature by examining the evolution of the educational expectations of a set of British Columbia high school graduates one, five, and 10 years after graduation, in relation to parental socioeconomic status and eventual postsecondary attainment. They find a strong correspondence between gender, parents' socioeconomic status, and educational attainment. Moreover, they find that educational expectations change little from the end of high school onward. We add to this literature by using the YITS-A (Youth in Transition Survey - Cohort A), which covers a set of students aged 15 to 23. This allows us to investigate, in the Canadian context, the role of the aspirations and expectations of children and their parents over the path of educational choices, beginning in high school and through to university. The use of this data set allows us to investigate the channels through which parents and peers influence educational pathways at an early stage of life in the context of differing socioeconomic backgrounds. Our results are broadly consistent with those of Andres et al. (2007).

Our empirical results suggest that, from the perspective of a policy goal to increase PSE attendance as well as to promote equitable educational attainment, the influence that parents have on children could be enhanced by providing expert counselling to students and their parents about the advantages of PSE. Based on our results, such policy measures should focus on children of low-income families because it is likely that the impact will be larger on this group.

The paper is organized as follows. We describe our motivation in Section 2, then discuss the data and empirical methodology in Sections 3 and 4, respectively. Our empirical results are presented and discussed in Section 5, and we provide remarks, policy suggestions, and conclusions in Section 6.

\section{Motivation}

As noted in the introduction, our goal is to better understand the channels through which parental, peer, and children's own aspirations and expectations affect the pathways of educational decision making (and attainment) in children of different genders and from different socioeconomic backgrounds. In this section, we describe informally how we model these relationships. Detailed statistical methodology is provided in Section 4. Although our data set precludes the detailed construction of socioeconomic indicators, parental income and education serve as proxies. The figure below describes the way we model the relationships involved in the educational choices made by children, beginning in high school. ${ }^{2}$

Entry into university requires the motivation or aspiration to attend university and the achievement of a high enough grade point average (GPA) to secure admission. Many factors directly and indirectly affect both grades and aspirations. The underlying factors include the socioeconomic status of the child's family, peer influence, and other influences, such as school and teacher characteristics, as illustrated by the arrows labeled "Eqn. 1" and "Eqn. 2." We argue in the section on empirical methodology that these mechanisms are subject to common but also separate forces. This provides us with an identification strategy, which in turn allows us to isolate causal effects. We demonstrate that these mechanisms, which influence each other, condition ultimate outcomes such as going to university. 


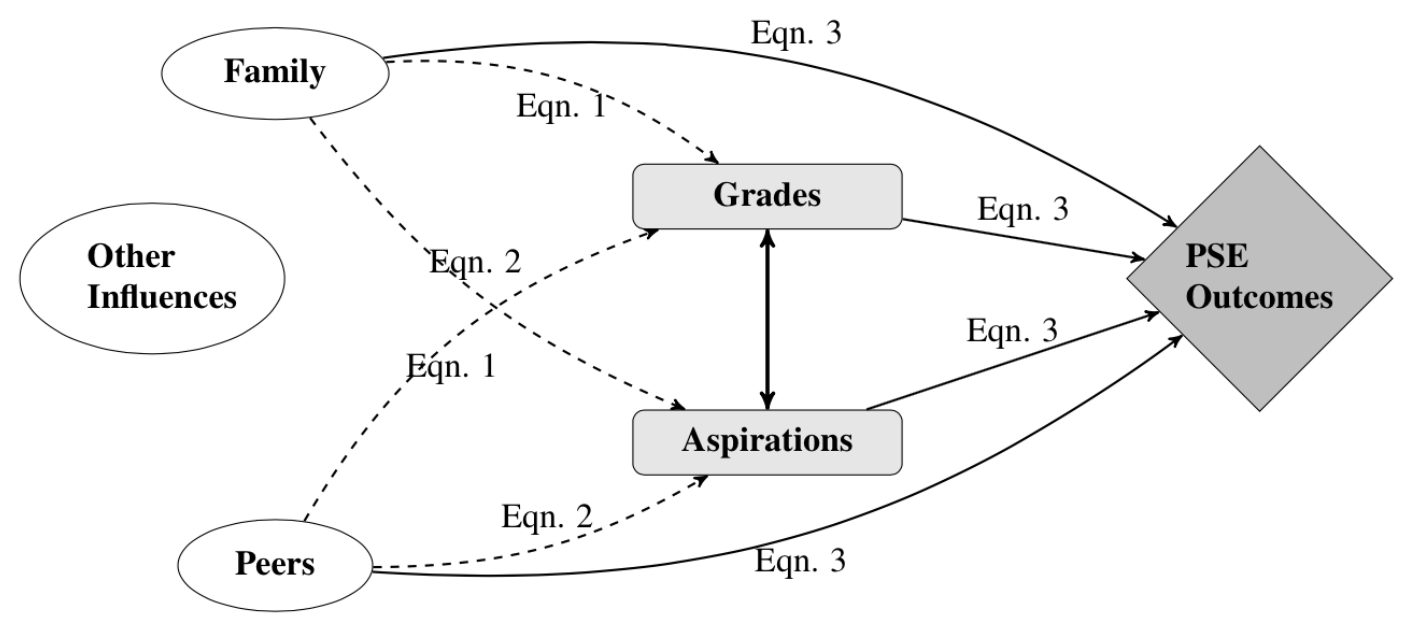

Figure 1. Model set-up

Our model explicitly describes how the path to university involves both aspirations and achievement (grades) through high school. A student with strong aspirations to attend university is likely to work harder at his/her school work and so achieve higher grades, while a student with higher natural ability, ceteris paribus, is likely to obtain higher grades, and this would reinforce expectations about eventual PSE. Using data from a Canadian survey, Looker (1997) finds that students who were doing well with course work went more frequently to their school counsellor for consultation and to get more information regarding higher education, which fed into their aspirations to attend university. This supports our presumption of bidirectional causality, as illustrated by the double arrow in the middle of Figure 1. Note that parental education levels may be correlated with their children's natural ability to achieve high grades in high school (through inheritance, with parental education correlated with innate ability) and may influence aspirations for university attendance (through the context of their cultural and social positions). This highlights the importance of providing a strong identification strategy, as will be discussed in the section on empirical methodology. Family background (socioeconomic status) also affects children's life decisions through social and human capital that are realized through other channels (see, e.g., Bourdieu \& Passeron, 1979; Coleman, 1988; Pineo \& Goyder, 1988). These independent influences are represented by the top arrow in Figure 1 (i.e., the direct connection to PSE Outcomes). It is important to know whether children's own aspirations can have an effect on their educational paths that is independent of what is "passed on" from the human and social capital of their parents. Otherwise, any policy designed to improve children's aspirations will not be effective. The decision to attend PSE as well as the ability to succeed are then influenced by all factors - family and peer influences, high school grades, and aspirations - as indicated by the model set-up of Figure 1.

We exploit the longitudinal nature of YITS-A and the wealth of student, parental, peer, and other variables that it contains to study this web of high school aspirations, grade achievement, parental influences, and peer influences on the eventual PSE attendance decisions and outcomes. We create an econometric model that allows us to analyze the role 
of parental and peer variables in determining student aspirations about further education and their high school performance, and how these factors affect university attendance. The wealth of data available in YITS-A allows us to select instruments to resolve the critical issue of the simultaneity involved between aspirations and grade achievements, as described above. We also recognize and exploit the temporal separation between high school aspirations/grade achievements and PSE outcomes when estimating our outcome equations.

Different from existing research in this area, which generally examines these issues at a point in time and often using data from a single institution (school or university), we are able to conduct a longitudinal analysis with data from several schools in Canada, thus accounting for the "historical" factor (Hanushek, Kain, Markman, \& Rivkin, 2003) in the aspirations updating process and decision making leading to university attendance. Also, as in Black, Devereux, \& Salvanes (2010), we analyze the peer effects on these children while they are teenagers, an age when they are most affected by their friends. Additionally, we are not limited to testing peer effects on GPA attainment; we are also able to study their influence on student decisions to attend university and to complete a degree.

A particular challenge we face is that the empirical literature on peer effects has yet to achieve a consensus on the extent to which they are causal. How one goes about disentangling identification issues in peer effects, for any specific application, is driven in part by data availability. In our study, we have a variety of quality characteristics of children that we can access in order to study peer effects. We use student-elicited characteristics of their group of peers, which potentially measure peer influences more effectively and are better proxies in terms of sampling and measurement error than the peer variables commonly used in the literature. These are constructed as an aggregate of students' characteristics in the classroom, school, etc.

Our findings suggest that the influence of closest friends as well as parents is pervasive. These groups affect the aspirations for university and grade performance while students are in high school. But they also affect eventual outcomes, such as university attendance or completion, directly and beyond any effects they may have had at the intermediate stage on high school aspirations and grades. That is, they have direct effects on outcomes as well as indirect ones, through aspirations and grades that themselves influence outcomes. These influences are conditioned by income group and gender. We believe that these effects are well established and net of the reflection problem, sample selection problem, and correlated effects that have been identified in the literature.

\section{Data}

\section{Sampling Characteristics}

The source of the data set we use is the YITS-A, a biennial longitudinal survey of five cycles. It follows the students involved from ages 15 to 23, in years 2000 to 2008, with interviews conducted in the spring of every two years of the time span indicated. In the first cycle, students as well as their parents and school principals were interviewed. The first cycle of this data set merges with the survey of the Organisation for Economic Cooperation and Development's Programme for International Student Assessment (PISA). Beginning with the second cycle, only the students were interviewed. The definitions of the variables we use in this empirical work are detailed in the Appendix. Given that the 
survey initially interviewed only 15-year-old students, most of them (93\%) are registered in the same grade level. In our subsample, we have 710 high schools with eleven students per school on average. Sampling in YITS-A was conducted based on a two-stage probability sampling; in the first stage, the high schools were chosen, and in the second stage, the students within each school were chosen. For student population representation purposes, we use probability weights in all our estimations. Since the stratum in this survey is the school, we use robust standard errors clustered by school.

\section{Summary Statistics}

In order to account for the heterogeneity across individuals, we use a set of variables measuring a student's own characteristics, peer characteristics, family background and parental characteristics, and school and teacher characteristics. Summary statistics are provided in Table A1 in the Appendix. The subscripts 15, 17, 21, and 23 on each of the variables indicate the age of the student and/or the corresponding year of the survey in which the question was asked (e.g., subscript 15 refers to a child being age 15 and/or the survey question being asked in 2000, which was the first year of the panel).

The students' own characteristic variables include the PISA reading score at age 15, hours spent working on homework in free time outside of school ("Hours worked on HW"), and an indicator of whether the student reports that a university degree is needed to work in the future job where the student plans to work at the age of 30 ("Think university required for job"). The PISA reading score is considered a reasonable proxy for cognitive abilities (Foley et al., 2009), provided one has controlled for the high school GPA (Frenette, 2009). ${ }^{3}$ In Table A1 we can see that female students have higher PISA score than males, they report spending more hours on homework, and they also are more likely than male students to report that their dream job requires a university degree. For the last two variables, the gender differences are more pronounced as the students get older (ages 15 to 17).

The school and teacher variables include a comprehensive set of indicators measuring different aspects of the composition and quality of high schools. These include the percentage of female students in the school, "teacher quality," "physical infrastructure shortage," "educational resource shortage," "teachers' morale and commitment," "student-teacher ratio," and "government-independent private," which accounts for differences in the academic achievement and expectations for future education of the students who attend these schools (Day, 2009). Referring to Table A1, in the Canadian high schools there are on average about 17 students per teacher, and $16 \%$ of the teachers have a thirdlevel qualification. Male students seem to enroll slightly more in private high schools than female students. The other school characteristics, such as "teacher quality" and physical infrastructure, are standardized indices based on a variety of properties for each index. The numerical values of these indices per se are not meaningful, but the relative values do reflect quality differences between schools.

As noted in the previous section, parents may influence their children's academic achievement and aspirations in several ways. The ability of parents to help finance their children's PSE is a plausible reason why a low family income may be a barrier to PSE. Income levels could also reflect many other indirect influences associated with socioeconomic status. For example, higher-income families may spend more on the nurturing of children 
in ways that allow them to better develop the cognitive and non-cognitive skills that condition successful entry into PSE. This process starts in childhood and continues into the teenage years. Another indirect influence might be through the general social environment, which differs, on average, across income classes and the education level of parents. Parental education may also be a signal of innate ability that is inherited by children. Hence, in our specifications we control for parental education and household income per capita. In our data set, apart from the above mentioned, we have further information about parents and the student's family background. Other variables are "sibling drop-out," "parent(s) immigrant," "non-birth parent," "parents' nurturance behaviour," "family educational support," and residence region indicators. As shown in Table A1, about nine percent of the students reported that at least one parent had been a landed immigrant in Canada, 12\% reported having non-birth parents, $23 \%$ (20\%) of the students had fathers (mothers) who held a university degree, and about six percent reported that a sibling had dropped out of high school. Female students reported on average a higher level of "family educational support" and of "parents' nurturance behaviour." This could be a matter of perception or reflect either a greater willingness of females to accept such support or parents offering more support to females. We are not able to disentangle these possible factors.

Family variables are based on a non-overlapping social group when it comes to parental expectations, and this feature helps with identification. "Parental expectations" is constructed as an indicator variable of whether the parents expect the child to attain at least one university degree in the future. This question in the parental survey aims to tease out parents' expectations based on their own desires/wishes for their child rather than on their child's ability. To ensure this further, we refer to a question in the survey asked of the parent right after the question about his/her expectations on the educational attainment of the child. The question is: "What is the main reason you hope your child will get this level of education?" Among the responses, 68.6\% of the parents responded "Better job opportunities or pay" and "Valuable for personal growth and learning," while only 9.8\% chose "Best match with child's ability." From Appendix Table A1 we can see that parents are more likely to have university expectations for their daughters (71\%) than for their sons $(62 \%)$.

Aiming to capture the influence of peers, we use several peer variables, most of which are self-reported by the student while one is a grade-level mean variable. The self-reported variables are the following. "Friends smoke" might be indicating general social attitudes. A teenager of age 15 who has made smoking a habit may be more likely to show negativity towards school and/or reflect an overall rebellious attitude. "Friends think it's okay to work hard" is a variable capturing the possibility that good students may face some negative behaviour from their classmates, such as being called a "nerd" or "teacher's pet" (Cooley, 2007; Foley et al., 2009). "Friends think completing HS is important" and "Friends think of going to PSE" serve as indicators of the general education aspirations of the close group of friends. On average, high school students report that "some" of the closest friends smoke cigarettes and that "most" of them think it is okay to work hard, think it is important to complete high school, and plan to pursue PSE after graduating from high school (see Table A1 and variable definitions in the Appendix).

Peer variables of this nature have advantages and disadvantages. On the one hand, we have no information about the actual identity of the "close group of friends." Neverthe- 
less, the information in this data set is based on individuals who are likely to be friends from the neighbourhood and thus attend the same high school as the reference student. Given that the information is reported by the students themselves, these variables are perceptions about their closest friends and the peer pressure by which the students feel most affected. This is a valuable characteristic of the elicited variables.

Rather than asking a subject directly about peers, the standard way of constructing a peer variable is to use the mean of the characteristics and/or outcomes of the group of friends, excluding the reference student (Ammermueller \& Pischke, 2009; Lee, 2007; Vigdor \& Nechyba, 2007 among many others). We construct one variable in this way, "grade-level average PISA," which captures the influence of the cognitive ability of the classmates on student $i$. In high school, children typically have different classmates in each course/class and so a purer measure of classmate peer effect is not feasible. However, the "quality" of children in the same year of schooling is closer than using the "quality" of children in the entire school.

\section{Empirical Methodology}

The regression analysis is conducted separately for the two periods that the survey covers: the high school year when the students were 17 years old (cycle 2 of the survey), and the PSE years, when they were 19-23 years old (cycles 3-5 of the survey), while also using data collected when the students were 15 years old (cycle 1 of the survey). Students are evaluated based on a set of credentials for access to an undergraduate university program. One of the main requirements of Canadian universities is the GPA threshold. Hence, a GPA higher than the threshold makes a student eligible to attend universities but may also motivate him towards this decision. The earlier the student has this intention, the more willing he will be to study harder to increase his GPA so that he can enter the program and be accepted by the desired university. Accordingly, if a higher GPA is achieved during high school, it is likely to induce an upward revision of aspirations, and so on. Thus, not only might grades affect aspirations, but aspirations may also affect grades. Based on this idea, we have two simultaneous reduced form equations to be estimated at age 17, when the students are still in high school. Equation (1), below, specifies the probability of achieving a high school GPA higher than $70 \%$ for student $i$ at school $s$ at age 17, as a function of: aspirations to attend university at $17\left(A s p_{i s, 17}\right)$; high school GPA at age 15; and (all at age 15 , or cycle 1 ) a vector of peer effects $\left(\right.$ Peers $\left._{i s, 15}\right)$, parental expectations (ParentExp $\mathrm{E}_{i s, 15}$ ), and a vector containing a comprehensive set of predetermined control variables $\left(\mathrm{X}_{i, 15}\right) \cdot \varepsilon_{i s, 17}^{\prime}$ is a $\mathrm{N}(0,1)$ error term.

$$
G P A_{i s, 17}=\alpha_{1}^{\prime} A s p_{i s, 17}+\alpha_{2}^{\prime} G P A_{i s, 15}+\text { Peers }_{i s, 15} \beta^{\prime}+\gamma^{\prime} \text { ParentExp }_{i s, 15}+X_{i, 15} \theta^{\prime}+\mathcal{E}_{i s, 17}^{\prime}
$$

Similarly, equation (2) defines the probability of having university aspirations.

$$
A s p_{i s, 17}=\alpha^{\prime \prime}{ }_{1} A s p_{i s, 15}+\alpha^{\prime \prime}{ }_{2} G P A_{i s, 17}+\text { Peers }_{i s, 15} \beta^{\prime \prime}+\gamma^{\prime \prime} \text { ParentExp } p_{i s, 15}+X_{i, 15} \theta^{\prime \prime}+\varepsilon^{\prime \prime}{ }_{i s, 17}
$$

We use instrumental variables to estimate the parameters of the above simultaneous equations (1) and (2), and we discuss this in detail in Section 5. For the PSE years, we estimate the following equation: 


$$
\text { Out }_{i s, \mathrm{c}}=\alpha_{1} A s p_{i s, \mathrm{c}-1}+\alpha_{2} G P A_{i s, 18}+\text { Peers }_{i s, 15} \beta+\gamma \text { ParentExp } p_{i s, 15}+X_{i, c-1} \theta+\varepsilon_{i s, \mathrm{c}}
$$

The (educational) outcome of student $i$ from school $s$ for cycle (year) $c,\left(\right.$ Out $\left._{i, \mathrm{c}}\right)$, is modeled as a function of: the aspirations dating one cycle earlier or two years earlier $\left(A s p_{i s, c-1}\right)$; high school overall grade at age $18\left(G P A_{i s, 18}\right)$; a vector of peer effects $\left(\right.$ Peers $\left._{i s, 15}\right)$ as well as parental expectations (ParentExp $p_{i s, 15}$ ), both at age 15; and a comprehensive set of predetermined control variables, $X_{i, c-1}{ }^{4}$ We use two definitions for PSE outcome: (i) "attended university" at ages 19, 21, and 23 separately, and (ii) "graduated university" at age 23. Among other issues, this specification explores whether peer pressure and parental influences during high school have any effect beyond their influence on grades and aspirations during high school - i.e., on actual university attendance and university degree completion.

A strand of the peer effect literature relevant to the present paper analyzes peer effects on the academic achievement of students, which are generally measured by standardized test scores or GPA. Hoxby (2000), Sacerdote (2001), and Lin (2010) find peers to be important influences on students' GPAs. Zimmerman (2003), Kramarz, Machin, and Ouazad (2008), Ammermueller and Pischke (2009), and Boucher, Bramoulle, Djebbari, and Fortin (2010) all find statistically significant, although small, peer effects on standardized test scores. Hanushek and Woessman (2007) question their results, stating that the causal effect of peer variables remains ambiguous, and Vigdor and Nechyba (2005) report no causal influence from peers on academic performance.

There are two major identification issues related to peer effect estimation discussed in the literature. The first issue is endogenous peer-group selection and why it is often argued that many empirical studies find implausibly large peer effects. Students self-select into schools (or via parental decisions) based on their own characteristics, some of which are observable and others not (like ability). To mitigate the problem of sample selection in our estimates, we control for a set of variables measuring characteristics of both parents and children, which also helped resolve the sample selection in Day (2009), Hanushek et al. (2003), and Ding and Lehrer (2007). Among these, the PISA score is a measure of a student's cognitive ability. Parental income, education, expectations, nurturing behaviour, and family educational support indices are the most comprehensive indicators of the student's family environment and socioeconomic background used in the literature. Additionally, the set of variables on school and teacher characteristics controls for a very rich variety of factors related to teachers, students, and educational resources that may affect the quality of the high schools. These variables help further the identification related to endogenous group selection because they provide the parents with important signals regarding the quality level of the high school they choose for their child. ${ }^{5}$ Hence, conditional on the most important characteristics from which self-selection arises, grade levels are likely to be constructed randomly. Also, even if one accepts the choice by parents to move to a certain neighbourhood, it is the age of the child that determines the grade year he will enter and, consequently, his classmates. Thus, as in Friesen and Krauth (2010), we think that, in this setting, it is plausible to assume that even when parents choose the school, the assignment to a grade level within a school happens exogenously, based mostly on the age of the child. A certain amount of randomness is inherent in this process and is beyond the control of the parents and the child. 
Further, in the event of self-selection, students may select into peer groups with similar unobserved characteristics that are stable, at least within the adolescent years, while they go to the same school and live in the same neighbourhood. We introduce the lagged grades and aspirations variable on the right-hand side of all our regressions to wipe out these common effects that otherwise would have been captured by the peer effects variable. This is based on the discussion of Hanushek et al. (2003, see p. 531), who take the first difference of the dependent variable in order to eliminate the "historical influences" but state that it is equivalent to adding the lag of the outcome in the right-hand side of the regression. In this way, no restriction is imposed on its coefficient. Hence, our peer effect estimates are free of self-selection and correlated effects after being conditioned on a variety of characteristics and factors based on which self-selection arises, and accounting for the unobserved correlated effects.

The second issue is the reflection problem - differentiating between the simultaneity of the impact of the peer group on the individual and the effect of the individual on the peer group. The reflection problem arises only if we try to estimate peer effects when the outcome of interest and the peer variable (constructed as an average of the same peer outcome) are concurrent, because they may simultaneously affect each other. In our setting, the only way to avoid the simultaneity problem is to use the past values instead of the concurrent peer effect variables, as in Hanushek et al. (2003). More precisely, we use the average of the PISA score at age 15 of current classmates. For the self-reported variables, we also use two-year lagged values. Hanushek et al. (2003, p. 535) state that even though this strategy will identify the peer effect coefficients, it will provide a lower bound estimate of the peer effect.

\section{Empirical Results}

Using data from YITS-A, Figure 2 shows the percentage of students who aspire to go to university at age 15 and 17 by gender. It also shows university attendance rates at age 19 . The black bars indicate a positive response and the grey bars a negative response. This figure shows how aspirations at 17 are updated, conditional on age 15 aspirations, and how this process leads up to university attendance. There are two points to take away from this chart. First, for both genders, the earlier they aspire to attend university, the more likely they are to actually attend university after graduating from high school. Second, male students start with lower aspirations at age 15 .

They are less likely to be persistent in their university aspirations - i.e., they are less likely to revise their aspirations upward ${ }^{6}$ and more likely to revise them downward than females. ${ }^{7}$ As a result, they are less likely to attend university at 19 (conditional on prior aspirations) than females. ${ }^{8}$ This information, which is consistent with the findings of Looker (1997) and Buchmann and Dalton (2002), confirms that separate investigations of the process leading up to PSE outcomes should be conducted for males and females.

The empirical results are analyzed by differentiating between the two time periods that the data covers. We analyze the high school years first, then the PSE years. In the results that follow in this section, we report marginal effects, defined as the probability change in the occurrence of the positive outcome (as indicated by the dependent variable) caused by a unit change from the mean value of the referred variable, holding all independent variables at their mean levels. When the independent variable is a dummy variable, 
the marginal effect represents the change in probability due to a discrete change of the dummy variable from zero to one. In the case of the categorical variables, the marginal effects measure the impact on the probability of the positive outcome due to moving one category up from the sample mean.

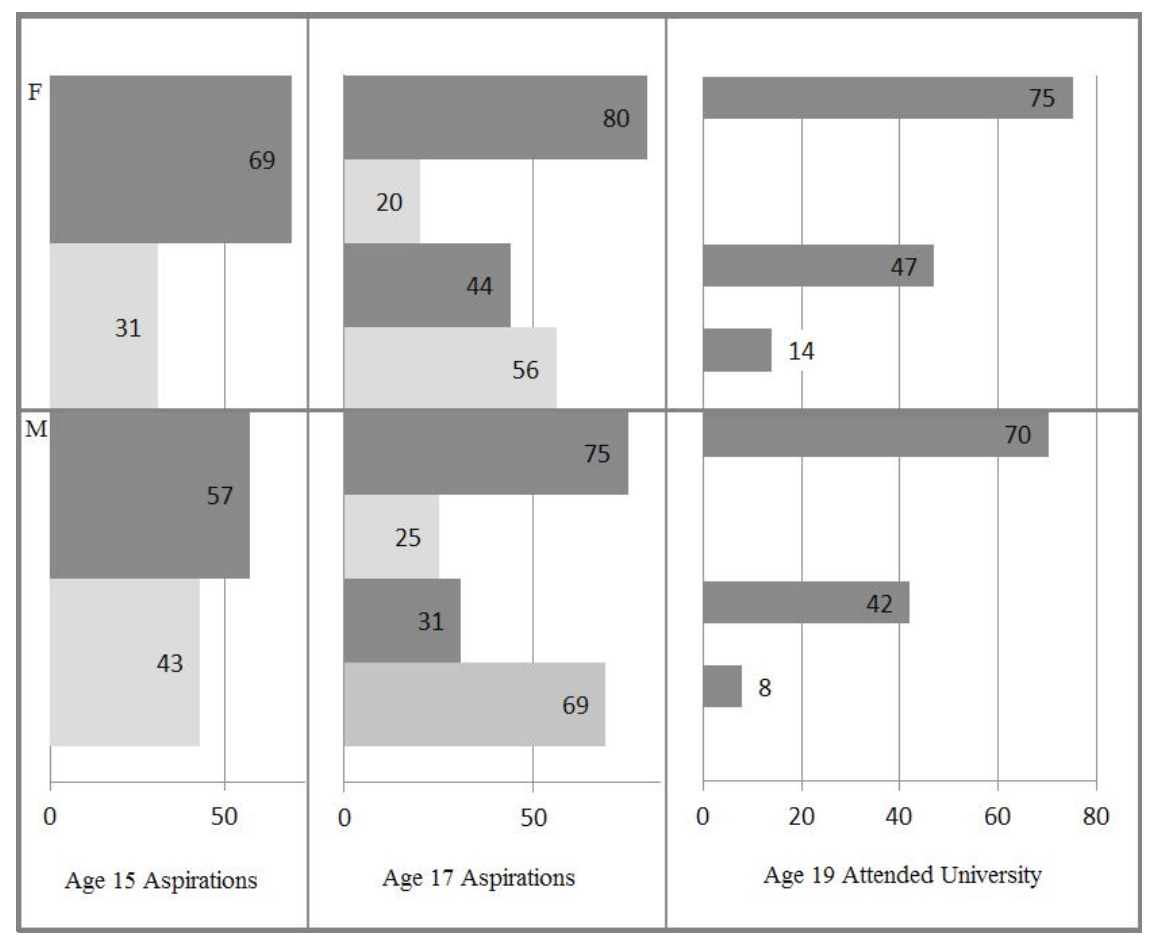

Figure 2. Proportion aspiring to attend a university program, conditional on past aspirations

\section{High School Years}

In this subsection, we estimate the effect of the own, peer, and parental variables on the probability of achieving a high school GPA above $70 \%$ and the probability of having university aspirations at age 17 - i.e., we estimate equations (1) and (2). The results for our variables of interest are shown in Table 1, with the full regression results shown in the Appendix, Table A2.

In order to address the simultaneity property between high school grades and aspirations, we employ an instrumental variable approach. The exclusion restriction for the aspirations variable is the change in the hours spent doing homework at home, after school, in the student's free time ( $\Delta$ Hours worked on HW) between ages 15 and 17. The exclusion restriction for the high school grades variable is the change in the student's belief about whether a university degree is required to work in the future job at age 30 ( $\Delta$ Think university required for future job). ${ }^{9}$ We acknowledge that in the levels, these two instruments may be driven by parental influences. Nevertheless, assuming parents affect students in a more or less consistent way through time, if we take the first difference for each of these two instruments, then the parental effect (individual effect for each student) will be differenced out. In this way, " $\Delta$ Hours worked on HW" captures the change in effort as a result of an individual choice only; " $\Delta$ Think university required for job" captures external information regarding the degree requirements or a change in preferences for the fu- 
ture job at 30 years old. The first step regression estimates are presented in Table 1 . The aspirations variable is strongly related to " $\Delta$ Think university required for job" for both genders. The parameter estimates are 0.186 for females ( 0.210 for males) and are statistically significant at the one percent confidence level. This is, therefore, a relevant instrument for the aspirations variable. Because the variable is based on future plans, it affects the student's motivation and, thus, aspirations for higher education. It may affect the academic performance during high school, but that may only happen through channels of aspiration formation. The probability of achieving a high GPA is positively correlated to " $\Delta$ Hours worked on HW," indicating that higher achievement comes with more effort. The coefficient estimates are also highly significant at the one percent significance level in the first step regressions for both genders. " $\Delta$ Hours worked on HW" has a direct effect on the grades and may affect aspirations indirectly only through grades.

Instrument validity, or the orthogonality of the instrument(s) with the error term, is another necessary condition that the instruments should satisfy. Since this is an assumption on which the instrumental variable (IV) estimator is based, it cannot be tested unless the number of IVs exceeds the number of endogenous variables. Instead, we refer to the Wald test of exogeneity to show there is reason to believe that the instrumental variable estimator is appropriate. This is a Hausman-type test of equality between the probit and ivprobit $^{10}$ specifications. For the maximum likelihood variant with a single endogenous variable, the test asks whether the error terms in the structural equation and the reducedform equation for the endogenous variable are correlated. If the test statistic is not significant, then there is not sufficient information in the sample to reject the null that there is no endogeneity. Table 1 contains the results. In all of the cases, we reject the null that our variable is exogenous. So, since the Wald test provides evidence that probit and ivprobit specifications are significantly different, we base our discussion on the results obtained by using the instrumental variable estimator for the time the students are still in high school.

The coefficients of the endogenous variables increase considerably after the instrumental variable approach is used in both grade and aspiration regressions. They are highly significant regardless of the estimator used. Referring to the ivprobit specifications, in both grades and aspirations equations, parental expectations have a statistically insignificant effect, but the effect of peers seems to prevail for both genders. Having friends with a smoking habit decreases the probability of achieving a high school GPA above $70 \%$ by 0.029 for females and by 0.040 for males. Having more friends who think it is okay to work hard improves by 0.019 the probability of girls achieving a high GPA. The classmates' average cognitive ability, as measured by "Grade-level average PISA," does not have an effect on the students' probability of doing well in school for either gender.

The probability of male students having university aspirations is negatively affected by this composition variable but positively affected by having more friends who smoke. In this case, "Friends smoke" may be capturing a network effect, and the benefit of having many close friends dominates the fact that they smoke. The "Grade-level average PISA" coefficient may be capturing an inferiority effect on male students for having above-mean ability classmates, rather than capturing a positive spillover effect of this peer characteristic. 


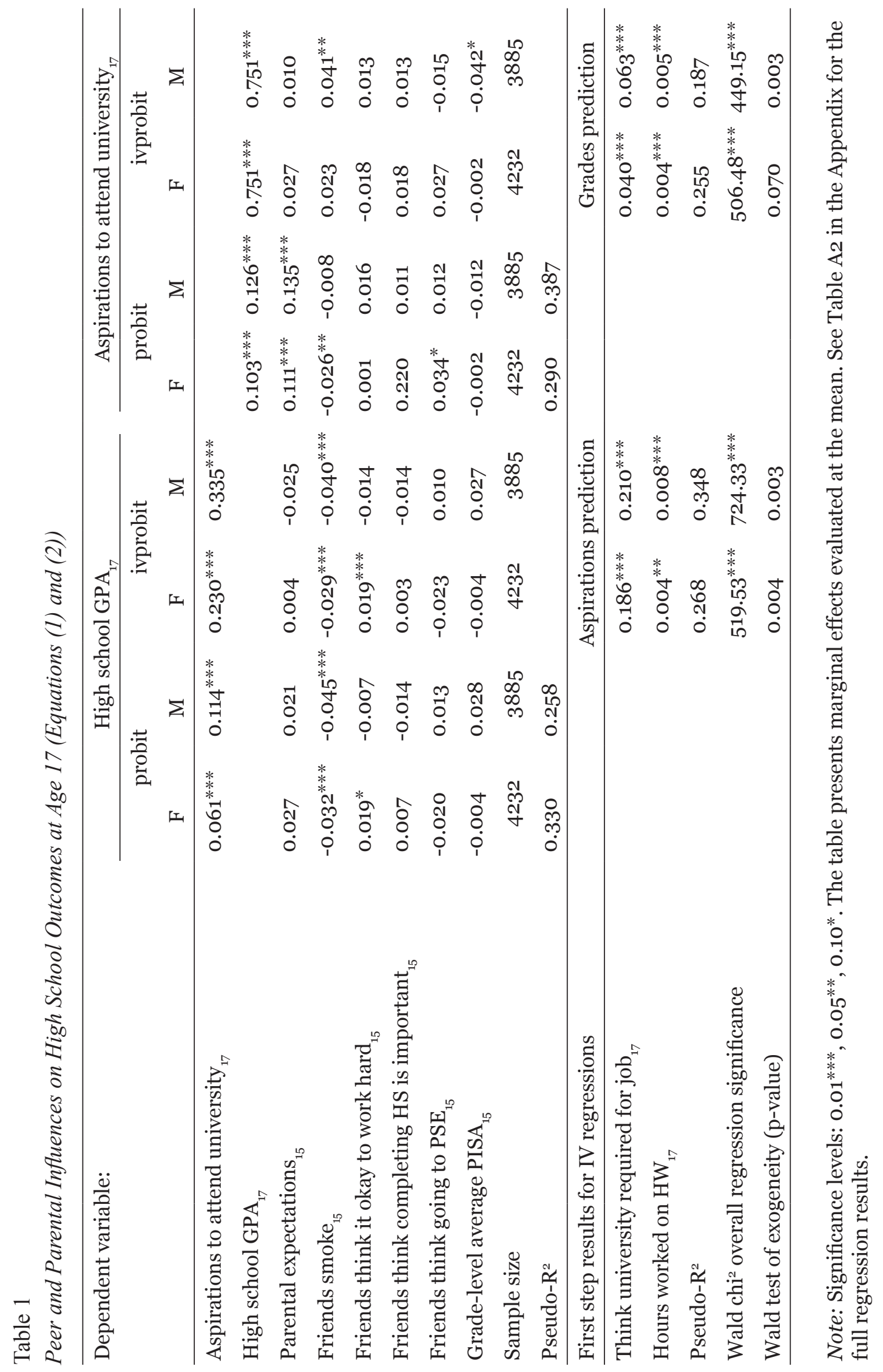




\section{PSE Outcomes}

We investigate two PSE outcomes: the probability of having "Attended university" and the probability of having "Graduated university" (see Table 2, below, and Table A3 in the Appendix for the full results). Since at least one year had passed since the students had graduated from high school, simultaneity between high school grades (age 18) and outcomes (ages 19, 21, and 23) is unlikely. Hence, we analyze the probit specifications for these regressions. The marginal effects of the family environment and peers on the PSE outcomes can be interpreted as additional effects - i.e., a marginal effect in addition to the effect of these variables on a student's overall high school GPA and aspirations during the high school years, which themselves have strong effects on the decision to attend university.

In Table 2, the lagged "Aspiration to attend university" variable has the highest marginal effect on the probability of attending university, at all ages and among all variables that also are significant predictors of outcomes. Holding all independent variables at their means, lagged university aspirations increases the probability of attending university by 0.307 for females and 0.245 for males. This marginal effect increases to 0.515 for females and 0.459 for males at age 21, and to 0.555 for females and 0.560 for males at age 23. Hence, the effect of the past aspirations on the actual decision to attend university is substantial.

The influence of parental expectations on the decision to attend university is highly significant for all ages, even after conditioning on parental education and income, "Family educational support," and "Parents' nurturance behaviour" (see Table A3). The estimated effect for females decreases with age, from 0.171 at age 19 to 0.150 and 0.148 at ages 21 and 23, respectively. At all ages, the marginal effects are higher for males than females, decreasing from 0.234 at age 19 to 0.152 at 21 and 0.165 at 23 .

It is interesting to see that the effect of "Friends smoke ${ }_{15}$ " is still present (even after controlling for past aspirations and high school GPA) in the outcomes of male students at ages 19 and 21 and female students at age 23. Associating with friends who smoke cigarettes decreases male students' probability of attending university by 0.051 and 0.061 , and that of females by 0.047 . Another peer variable influencing the probability of attendance is "Friends think going to PSE $_{15}$ " This variable influences male students positively by increasing their probability of attending university by 0.153 at age 23 , for a one-category increase above the mean. Regarding peer cognitive ability, "Grade-level average PISA" is insignificant in all of the regressions after controlling for grades and aspirations during high school. Therefore, it seems that after graduating from high school, female students are mainly affected by parental expectations, whereas male students are affected by both parental expectations and their peers' aspirations and attitudes. In the last two columns of Table 2, we show the regression results for the outcome "Graduated university" conditional on the lag of "Attended university," which, as expected, has the highest influence on the outcome (see Table A3). Females' probability of graduating is negatively affected by "Friends smoke ${ }_{15}$," decreasing by 0.039 when they associate with more of such friends.

Apart from the above variables of interest, it is worth noting that the university attendance decision is significantly affected by other control variables (see Table A3), such as the lagged "Think university required for job," PISA score, parental education, and "Sibling drop-out" (females only). These results are in line with the findings in the literature (Christofides et al., 2008; Knighton \& Bussiere, 2006; Rampino \& Taylor, 2013). In order 
to account for student immigrant status, ethnicity, and race, we replicated the results with variables available in our survey that tease out these characteristics. In our sample, only 7.3\% of the students are non-Caucasian, $95.2 \%$ are Canadian born, $84.5 \%$ report English as their mother tongue, and $8.6 \%$ report French as their mother tongue. Conditioning for these variables in our regressions resulted in negligible changes in the parameter estimates of our variables of interest. In general, their coefficient estimates lacked a statistically significant association with the dependent variable. Also, the indicators for race and immigrant status have a high correlation with "Parent(s) immigrant" (0.689 and -0.598, respectively), which already accounts for this aspect of individual heterogeneity. Hence, for the above reasons, we leave these variables out of the vector in all our specifications.

We take a further step and estimate the reduced form model of equation (3) for three distinct quartiles of the parental income distribution: the lowest $25 \%$, the middle $50 \%$, and the top 25\%. Results are presented in Table 3 for age 23. We also do a similar analysis for ages 19 and 21, and the results for these are shown in Tables A4 and A5 in the Appendix. We concentrate on age 23 regression results because even those students who choose to delay entrance to PSE have enrolled in a PSE program by this age if they ever intend to do so. From Table 3, we note that for all income groups and for both genders, university aspirations have an important effect on the decision to attend university. The magnitude is generally higher for the low-income group. Parental expectations play an important role in increasing the probability of attendance, except for male students of high-income families. The marginal effect estimates decrease as we go from low- to high-income groups. For female students of low-income families, the coefficient estimate (0.200) is almost twice that of the high-income group (0.105). "Friends smoke ${ }_{15}$ " has a negative effect on the probability of university attendance for females of middle- and high-income families ( -0.048 and -0.045 , respectively).

Friends with aspirations to go to PSE positively affect students from high-income families. Notice that, conditional on past aspirations, only male students of high-income families are influenced by peers. Male students of the other two income groups are only affected by parental expectations. The results are similar for the ages 19 and 21 regressions. In the last two rows of Table 3, we show the attendance rates (or the mean of the dependent variable) for each income group. Attendance rates for females are higher than for males in all cases. We note that the university attendance gap between female and male students is highest for the low-income family students (16\%) and substantially lower for the middle- (10.2\%) and high-income (8.4\%) family students. Therefore, any attempt to balance the gender gap should be concentrated on the low-income group students.

\section{Conclusion}

In this paper, we use a rich Canadian dataset to analyze the role of a number of variables, including parental influences and peer effects, in determining grade achievement and the formation of aspirations about further education in high school students. We then investigate how these aspirations affect the probability of attending university and the probability of completing a university degree. Unlike much existing research in this area, which generally examines the issue based on a point in time and with data from a single institution (school or university), we are able to conduct a longitudinal analysis with data representative of Canadian youths. 


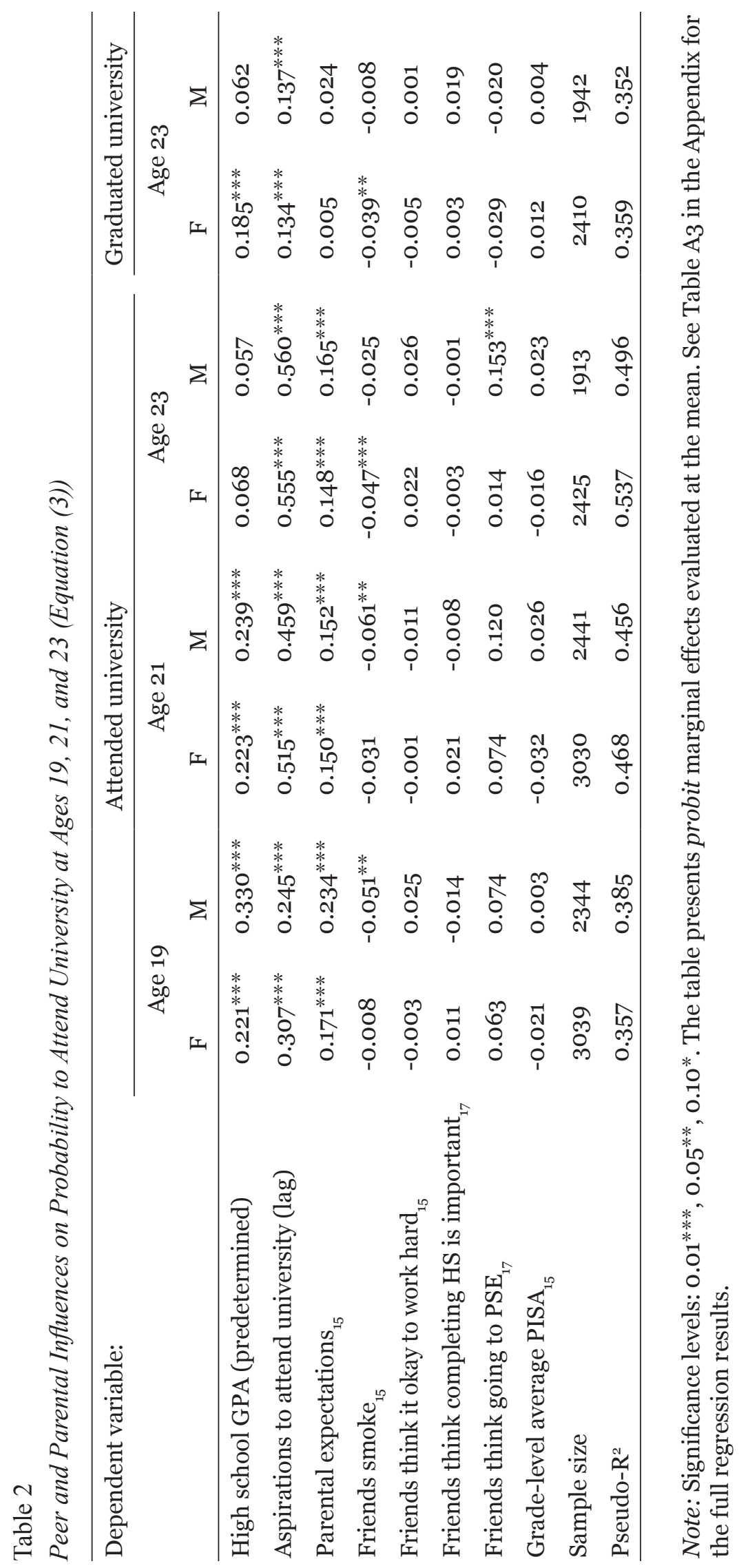




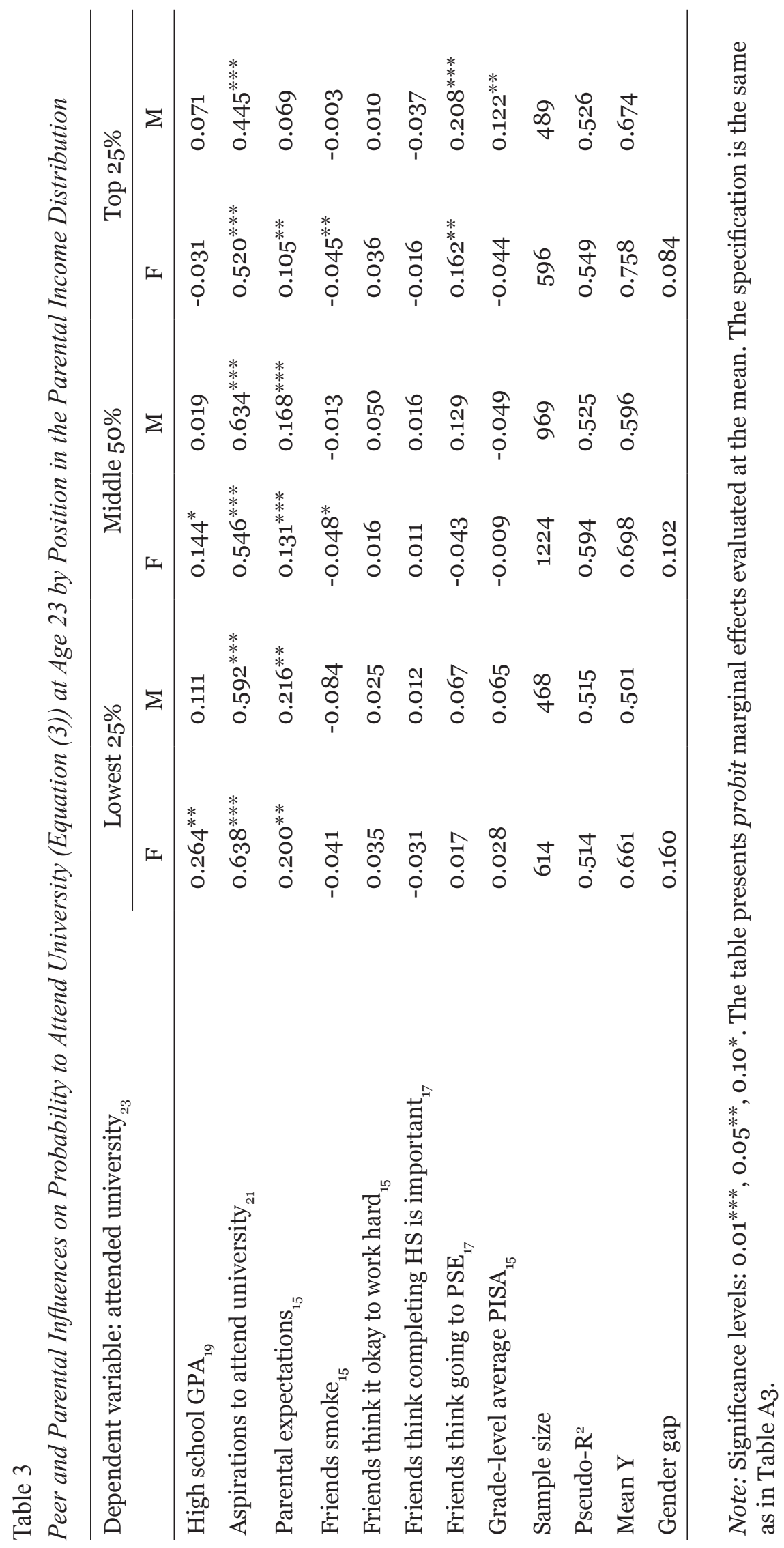


Regarding the high school period, after correcting for the simultaneity between grades and aspirations, we find that having aspirations to attend university is at least as important as cognitive ability in increasing the probability of high academic performance. During high school, students' aspirations and grades are affected more by their closest friends than they are affected by their parents', teachers', or high school's characteristics.

We conclude that the students' high school grades and aspirations for further education are important determinants of the probability to attend university. Conditional on a measure for cognitive ability and other variables, having a GPA above 70\% increases the probability of going to university by about 0.220 for females and 0.330 for males. Having aspirations to attend university during high school increases the probability of attendance by 0.307 for females and 0.245 for males at age 19. At ages 21 and 23, the marginal effects are higher in magnitude. For male students, the probability of attending university after graduating from high school is affected by parental expectations and peer effects, above and beyond the effects that these variables have had on the evolution of their overall GPA and on the evolution of their aspirations during the high school years. Female students' probability of attending university is affected (through their direct channel) by parental expectations at all ages, but by peers only at age 23. Although the peer variables' marginal effects are relatively small, the marginal effects from the parental expectations are substantial. The increase in probability of attendance varies with age, between 0.148 and 0.171 for females and between 0.152 and 0.234 for males. When we split the sample by income group, we find that peer effects influence females' probability of attending university for female students of middle- and higher-income families. In the case of males, only those from the high-income group are affected by the peer variables.

Our analysis complements the existing sociological and economics-based literature concerning the factors that influence educational aspirations and achievements. Our results are especially complementary to those of Andres et al. (2007), who find consistent patterns of educational expectations regarding university education beyond the high school years. We find that children's path to university is strongly influenced by the development of aspirations to attend university through their high school years. This is especially apparent for families with low socioeconomic status, as we find when separating into quartiles the data according to family income; the marginal effects are highest for the lowest quartile. These findings suggest that, from the perspective of a policy goal to increase the level and equitability of university attendance, it would appear that a strong effect could be created by exploiting the influence that parents have on children by providing - to students but especially to their parents - information about the advantages of PSE. Mills and Gale (2004) investigate through a survey instrument why parents from low-income families in Australia do not engage more with the school (e.g., attend parent-principal meetings), while Looker (1997) finds that a majority of students who have completed a university degree report that they valued their parents' expectations. Our results emphasize the importance of understanding these factors. Having parents and their children attend the same information meetings could be very productive, as this not only would influence the expectations of both parents and children but also reinforce the children's belief about their parents' interest in possible PSE attendance. It is important that parents be aware of the difference attaining PSE will make in their children's future lifestyle (e.g., higher income, more satisfying jobs, and lower probability of unemploy- 
ment). These students will have a peer effect on their friends, creating a social multiplier effect along with the direct effect on the reference child. Based on our results, the policy measure should focus mainly on the children of low-income families because it is likely that the impact will be largest in this group. Note, also, that this group has a higher gender gap in university attendance than the middle- and high-income groups. Of course, it may be difficult to target by family income for a given school. But additional resources for such a program could be made available for schools in lower-income districts.

\section{Notes}

1. As noted in Andres, Adamuti-Trache, Yoon, Pidgeon, and Thomsen (2007, p. 136), "students' socioeconomic locations are indeed critical in understanding the close relationship between educational expectations and outcomes."

2. Several relevant (or related) variables (as allowed by our data set), such as family income, are included in our empirical analysis.

3. The equation numbers are used later in the paper in order to describe how the empirical methodology executes our conceptual model.

4. We use reading test scores of PISA, rather than math or science test scores, because the number of students taking the reading test is higher by about $50 \%$ than the number taking the math and/or science tests.

5. See Figure 1 for a flow chart describing the relations involving the three equations. For simplicity, not all influences in equations (1), (2), and (3) are shown.

6. In some jurisdictions, students/parents have little to no choice about which high school to attend, as this is determined by the geographic location of the family home. However, it has been argued that parents may choose where to live in part based on school characteristics. Our estimation methodology allows us to avoid possible endogeneity issues that might arise from such a phenomenon.

7. At the age of $17,44 \%$ of the females who at 15 had not aspired to go to university updated their aspirations upwards, but only $31 \%$ of the males did so.

8. On the other hand, $20 \%$ of the female students who at 15 had aspired to attend university updated their aspirations downward at 17, whereas the corresponding number for males is $25 \%$.

9. Out of the $69 \%$ of females who have aspirations to attend university at $15,80 \%$ of these maintain the same aspirations at 17 , most of whom (75\%) end up attending university at 19 . In the case of male students aged $17,75 \%$ of those who had university aspirations at 15 keep the same response, but out of this group only $70 \%$ actually go on to university. So, for the group of students who had university aspirations at both 15 and 17, the number of females attending university at 19 is five percent higher than that for males. Of the females who upgraded their aspirations at 17 (44\%), 47\% actually attended university by the age of 19 . The corresponding number for the male group is 42\%. Even among the students who never aspired to go to university, females are six percent more likely to attend university than males (14\% rather than eight).

10. In order to deal further with the simultaneity issue in case the chosen instruments used were insufficient, we strengthened the identification of equations (1) and (2) by also excluding from each specification the cross-lagged terms. This introduces an extra degree of identification beyond what we did with the use of the instruments described above. 
11. The STATA command ivprobit is a maximum likelihood instrumental variable estimator used when both the endogenous and the dependent variables are binary.

12. One might argue that because these two sets of peer variables are by construction different (identification issues arise for each), including both sets simultaneously in the regressions might be driving our results. We repeated the analysis by including each set of peer variables separately, and the results are quantitatively and qualitatively similar to the ones presented in the paper. These tables are available on request.

\section{Acknowledgements}

While the research and analysis are based on data from Statistics Canada, the opinions expressed do not represent the views of Statistics Canada.

\section{References}

Ammermueller, A., \& Pischke, J.-S. (2009). Peer effects in European primary schools: Evidence from progress in international reading literacy study. Journal of Labor Economics, 27, 315-348.

Andres, L., Adamuti-Trache, M., Yoon, E.-S., Pidgeon, M., \& Thomsen, J. P. (2007). Educational expectations, parental social class, gender and postsecondary attainment: A 10-year perspective. Youth \& Society, 39(2), 135-163.

Black, S. E., Devereux, P. J., \& Salvanes, K. G. (2010). Under pressure? The effects of peers on outcomes of young adults. Working Paper Series, No. WP10/16. Dublin, Ireland: University College Dublin Centre for Economic Research.

Boucher, V., Bramoulle, Y., Djebbari, H., \& Fortin, B. (2010, January). Do peers affect student achievement? Evidence from Canada using group size variation. Discussion Paper No. 4723. Bonn, Germany: Institute for the Study of Labor.

Bourdieu, P., \& Passeron, J.-C. (1979). The inheritors: French students and their relation to culture (R. Nice, Trans.). Chicago, IL: University of Chicago Press.

Buchmann, C., \& Dalton, B. (2002). Interpersonal influences and educational aspirations in 12 countries: The importance of institutional context. Sociology of Education, 75(2), 99-122.

Christofides, L. N., Hoy, M., Li, Z. J., \& Stengos, T. (2008). The evolution of aspirations for university attendance. In R. Finie, R. E. Mueller, A. Sweetman, \& A. Usher (Eds.), Who goes? Who stays? What matters? Accessing and persisting in post-secondary education in Canada (p. 109-134). Kingston, Canada: McGill-Queen's University Press.

Coleman, J. S. (1988). Social capital in the creation of human capital. American Journal of Sociology, 94, S95-S120.

Cooley, J. (2007, November). Alternative mechanisms of peer achievement spillovers: Implications for identification and policy. WCER Working Paper No. 2008-08. Madison, WI: Wisconsin Center for Education Research, University of Wisconsin-Madison.

Day, K. (2009). The effect of high school resources on investment in post-secondary education in Canada. Toronto, Canada: MESA Project. Retrieved from http:// higheredstrategy.com/mesa/pub/pdf/MESA2008_Day.pdf 
Ding, W., \& Lehrer, S. F. (2007). Do peers affect student achievement in China's secondary schools? The Review of Economics and Statistics, 89(2), 300-312.

Finnie, R., \& Mueller, R. (2008). The backgrounds of Canadian youth and access to post-secondary education: New evidence from the Youth in Transition Survey. In R. Finnie, R. E. Mueller, A. Sweetman, \& A. Usher (Eds.), Who goes? Who stays? What matters? Accessing and persisting in post-secondary education in Canada (pp. 79-108). Kingston, Canada: McGill-Queen's University Press.

Foley, K., Gallipoli, G., \& Green, D. A. (2009, September). Ability, parental valuation of education and the high school drop-out decision. IFS Working Paper No. Wo9/21. London, UK: Institute for Fiscal Studies.

Frenette, M. (2009, October). Career goals in high school: Do students know what it takes to reach them, and does it matter? Analytic Studies Branch Research Paper Series 11Foo19M, No. 320. Ottawa, Canada: Statistics Canada.

Frenette, M., \& Zeman, K. (2007, September). Why are most university students women? Evidence based on academic performance, study habits and parental influences. Analytical Studies Branch Research Paper Series 11Foo19, No. 303. Ottawa, Canada: Statistics Canada.

Friesen, J., \& Krauth, B. (2010). Sorting, peers, and achievement of aboriginal students in British Columbia. Canadian Journal of Economics, 43, 1273-1301.

Hanushek, E. A., Kain, J. F., Markman, J. M., \& Rivkin, S. G. (2003). Does peer ability affect student achievement? Journal of Applied Econometrics, 18, 527-544.

Hanushek, E. A., \& Woessman, L. (2007, February). The role of school improvement in economic development. Working Paper No. 1911. Munich, Germany: CESifo.

Hanushek, E. A., \& Woessman, L. (2008). The role of cognitive skills in economic development. Journal of Economic Literature, 46(3), 607-668.

Hoxby, C. (2000). Peer effects in the classroom: Learning from gender and race variation. NBER Working Papers No. 7867. Cambridge, MA: National Bureau of Economic Research.

Jacob, B. A. (2002). Where the boys aren't: Non-cognitive skills, returns to school and the gender gap in higher education. Economics of Education Review, 21, 589-598.

Johnson, D., \& Rahman, F. (2005). The role of economic factors, including the level of tuition, in individual university participation decisions in Canada. Canadian Journal of Higher Education, 35(3), 83-99.

Knighton, T., \& Bussiere, P. (2006). Educational outcomes at age 19 associated with reading ability at age 15. Culture, Tourism and the Centre for Education Statistics Research Paper No. 43. Ottawa, Canada: Statistics Canada.

Knighton, T., \& Mirza, S. (2002). Postsecondary participation: The effects of parents' education and household income. Education Quarterly Review, 8(3), 25-32.

Kramarz, F., Machin, S., \& Ouazad, A. (2008). What makes a test score? The respective contributions of pupils, schools, and peers in achivement in English primary education. Discussion Paper No. 3866. Bonn, Germany: Institute for the Study of Labor. 
Lee, L. (2007). Identification and estimation of econometric models with group interactions, contextual factors and fixed effects. Journal of Econometrics, 14O(2), 333374 .

Lin, X. (2010). Identifying peer effects in student academic achievement by spatial autoregressive models with group unobservables. Journal of Labor Economics, 28(4), $825-860$.

Lochner, L. J., \& Moretti, E. (2004). The effect of education on crime: Evidence from prison inmates, arrests and self-reports. American Economic Review, 94(1), 155-189.

Looker, D. E. (1997). In search of credentials: Factors affecting young adults' participation in postsecondary education. Canadian Journal of Higher Education, $27(2 / 3), 1-36$.

Milligan, K., Moretti, E., \& Oreopoulos, P. (2004). Does education improve citizenship? Evidence from the United States and the United Kingdom. Journal of Public Economics, 88(9-10), 1667-1695.

Mills, C., \& Gale, T. (2004). Parent participation in disadvantaged schools: Moving beyond attributions of blame. Australian Journal of Education, 48(3), 268-281.

Pineo, P. C., \& Goyder, J. (1988). The growth of the Canadian education system: An analysis of transition probabilities. Canadian Journal of Higher Education, 18(2), 37-54.

Rampino, T., \& Taylor, M. (2013). Gender differences in educational aspirations and attitudes. Working Paper Series, No. 2013-15. Colchester, UK: Institute for Social and Economic Research.

Sacerdote, B. (2001, May). Peer effects with random assignments: Results for Dartmouth roommates. The Quarterly Journal of Economics, 116(2), 681-704.

Vigdor, J. and Nechyba, T. (2007). Peer effects in North Carolina public schools. In Woessmann, L. \& Peterson, P. (Eds.), Schools and the Equal Opportunity Problem (p. 73-102). Massachusetts Institute of Technology Press.

Zhao, J., Corak, M., \& Lipps, G. (2003). Family income and participation in postsecondary education. Analytical Studies Branch Research Paper Series 2003210e, No. 210. Ottawa, Canada: Statistics Canada.

Zimmerman, D. J. (2003). Peer effects in academic outcomes: Evidence from a natural experiment. The Review of Economics and Statistics, 85(1), 9-23.

\section{Contact Information}

Joniada Milla, University of Guelph and CORE joniada.milla@uclouvain.be

Louis N. Christofides (PhD, UBC 1973) was on faculty at the University of Guelph (19722002) and the University of Cyprus (2002-2013), serving as Chair of the Department of Economics at both institutions and as Dean of the Faculty of Economics and Management at the University of Cyprus (2006-2011). He is currently Professor Emeritus at 
both institutions. He is Research Associate of CESifo and a Research Fellow of IZA. He has served on the Governing Board of the Central Bank of Cyprus and is currently VicePresident of the National Economic Council of Cyprus. He has published extensively in professional journals.

Michael Hoy joined the Department of Economics at the University of Guelph in 1985, following positions at Queen's University and the University of Western Ontario. He received a Ph.D. from the London School of Economics in 1982. His research topics include information in insurance markets, inequality and poverty measurement - theory and applications, and various issues in public economics. His research has been published in journals including the American Economic Review, Quarterly Journal of Economics, Journal of Economic Theory, Journal of Public Economics, Geneva Papers on Risk and Insurance, and the Journal of Risk and Insurance.

Joniada Milla is currently a post-doctoral fellow at the Center for Operations Research and Econometrics (CORE), Catholic University of Louvain. She holds a Ph.D. (2013) and a Master's degree (2008) in Economics from the University of Guelph. Her research interests lie in the fields of Applied Econometrics, Economics of Education and Labor Economics. In particular, her research focuses on post-secondary education attendance, on the benefits associated with education selectivity and policy implications. Currently, Joniada is working on education efficiency and Value Added Models in post-secondary education.

Thanasis Stengos is Professor of Economics at the University of Guelph in Ontario, Canada and he is Deputy Director of the Rimini Center for Economic Analysis in Rimini, Italy. He has held visiting positions at Queen's University, the University of Cyprus, the University of Bologna at Rimini and the European University Institute in Florence as a Jean Monnet Fellow. He served in the editorial board of the Canadian Journal of Economics and he is currently an associate editor of the Journal of Applied Econometrics, Economics Letters, Empirical Economics and the co-editor of the Review of Economic Analysis.

\section{Appendix}

\section{Variable Definitions}

Aspirations to attend university. Dummy Variable. 1 if the highest level of education respondent think he/she will get/would like to get is a university diploma or certificate below Bachelor's, a Bachelor's Degree or higher (or one university degree or more than one university degree for cycles 1,2); o otherwise.

Attended university. Dummy Variable. 1 if response to the question "Highest level of PSE taken across all programs and institutions?" is a university diploma or certificate below Bachelor's, Bachelors degree or higher, o otherwise. The respondents may have graduated from this level, may still be in the program or maybe left the program.

Educational resource shortage ${ }_{15}$. School principals' reports on the extent to which learning by 15-year-olds in their school was hindered by: lack of instructional material; not enough computers for instruction; lack of instructional materials in the library; lack of 
multi-media resources for instruction; inadequate science laboratory equipment; and, inadequate facilities for the fine arts. A standardized (zero mean and unit standard deviation) index of the quality of schools' educational resources is derived after.

Family educational support ${ }_{15}$. Student's reports on the frequency that his/her parents and siblings work with them on their schoolwork. A PISA index is then derived.

Father university ${ }_{15}$ (Mother university ${ }_{15}$ ). Dummy Variable. 1 if the father (mother) has a university certificate or diploma below Bachelor's, a Bachelor's Degree or higher; o otherwise.

Friends smoke ${ }_{15}$. Categorical Variable. Equals o if student response to the question "Think about your closest friends. How many of these friends smoke cigarettes?" is "None of them"; 1 if "Some of them"; 2 if "Most of them"; 3 if "All of them."

Friends think completing $H S$ is important ${ }_{15}$. Categorical Variable. Equals o if student response to the question "Think about your closest friends. How many of these friends think completing high school is very important?" is "None of them"; 1 if "Some of them"; 2 if "Most of them"; 3 if "All of them." This variable is also available at age 17 (cycle 2).

Friends think going to $P S E_{15}{ }^{\circ}$ Categorical Variable. Equals o if student response to the question "Think about your closest friends. How many of these friends are planning to further their education or training after leaving high school? " is "None of them"; 1 if "Some of them"; 2 if "Most of them"; 3 if "All of them." This variable is also available at age 17 (cycle 2).

Friends think it okay to work hard ${ }_{15^{\circ}}$ Categorical Variable. Equals o if student response to the question "Think about your closest friends. How many of these friends think it's okay to work hard at school? " is "None of them"; 1 if "Some of them"; 2 if "Most of them"; 3 if "All of them."

Government-independent private ${ }_{15}$. Dummy Variable. 1 if the school is government-independent private, $\mathrm{o}$ otherwise. Government-independent private schools were coded as 1 , if the school principal reported that the school was controlled and managed by a non-governmental organization (e.g., a church, a trade union or a business enterprise) or if its governing board consisted mostly of members not selected by a public agency, where it received less than 50 per cent of its core funding from government agencies.

Grade-level average PISA ${ }_{15}$. The average PISA score of the students in the same gradelevel excluding the reference student.

Graduated university. Dummy Variable. 1 if response to the question "What is the highest degree you have attained?" is a university diploma or certificate below Bachelor's, a Bachelor's degree or higher; o otherwise.

High School GPA. Dummy Variable. 1 if the students reports to have a high school grade point average (GPA) up to the time of interview within the range of $70-79 \%$ or higher.

Hours worked on HW. Categorical Variable. Equals o if "No time" spent working on homework outside class during free periods and at home within a week; 1 if "less than 1 hour a week"; 2 if "1-3 hours a week"; 5.5 if "4-7 hours a week"; 11 if " 8-14" hours a week; 15 if "more than 15 hours a week." This variable is available at age 15 and 17 (cycles 1 and 2).

Non-birth parent ${ }_{15}$. Dummy Variable. 1 if the parent is not by birth (i.e. by adoption, foster, step parent or guardian); o otherwise. 
Parental expectations ${ }_{15^{\circ}}$ Dummy Variable. 1 if response of the parent to the question "What is the highest level of education that you hope child will get?" is "One university degree" or "More than one university degree"; o otherwise.

Parental income ${ }_{15}$. Variable indicating the combined (respondent and spouse/partner) total income divided by the number of the household members and standardized so that it has zero mean and unity standard deviation. Total income is derived from a sum of the nine income sources collected during the parent interview. They are Wages and Salaries before deductions, including bonuses, tips and commissions; Net Income from Farm and Non-Farm Self-employment (after expense and before taxes); Employment Insurance benefits (before deduction); Canada Child Tax Benefits and provincial child tax benefits or credits (including Quebec Family Allowance); Social Assistance (welfare) and Provincial Income Supplements; Support program received, such as spousal and child support; Other Government Sources, such as Canada or Quebec Pension Plan Benefits, Old Age Security Pension, or Workers' Compensation Benefits; Goods and Service Tax Credit/Harmonized Tax Credit received in 1999; and Other Non-Government sources including dividends, interest and other investment income, employment pension, RRIFs and annuities, scholarships, and rental income.

Parent(s) immigrant ${ }_{15}$. Dummy Variable. 1 if at least one the parents has ever been a landed immigrant to Canada; o otherwise.

Parents' nurturance behavior ${ }_{15}$. Parent's reports on the frequency with which parents: praise child; listen to child's ideas and options; make sure child knows that they are appreciated; speak of good things those children does; and, seem proud of the things child does. A YITS scale variable is derived from this information and we standardize it so that it has zero mean and unity standard deviation.

Percent females ${ }_{15}$. This index is the ratio between the number of girls and the total enrollment (the number of boys plus number of girls), that is the number of girls in the school divided by the total enrollment.

Physical infrastructure shortage ${ }_{15}$. School principals' reports on the extent to which learning by 15 -year-olds in their school was hindered by: poor condition of buildings; poor heating and cooling and/or lighting systems; and, lack of instructional space. A standardized (zero mean and unit standard deviation) index is derived from the above information.

PISA score. Programme for International Student Assessment (PISA) reading test score expressed in per 100 points.

Residence region indicators. Rural Dummy Variable: Indicator of rural vs. urban geography, based on the Statistical Area Classification, based on the 1996 Census geography equals 1 if "Rural"; $o$ if "Urban." Atlantic Dummy Variable: 1 if the student is residing in either of the four provinces Newfoundland, Prince Edward Island, Nova Scotia or New Brunswick; o otherwise. Likewise, we build three other dummy variables indicating residence in the provinces of Manitoba or Saskatchewan, Alberta, British Columbia. The province of Quebec is excluded from the analysis due to their CEGEP system, unlike the other provinces. The omitted category is residence in Ontario.

Sibling drop-out ${ }_{15}$. Dummy Variable. 1 if any of the child's brother's or sisters is a high school drop-out; o otherwise.

Students-teachers ratio ${ }_{15}$. This index is the school size divided by the total number of teachers (part-time teachers contribute 0.5 and full-time contribute 1.0). 
Teacher quality ${ }_{15}$. Number of full-time teachers who have a third level qualification (i.e. a Bachelor's degree with a major) plus 0.5 times the number of part-time teachers with a third level qualification divided by the total number of teachers in a school. The third level qualifications counted are a degree in English and literature, in mathematics and science (chemistry, physics, biology or earth science).

Teachers' morale and commitment ${ }_{15}$. The extent to which school principals agreed with the following statements: the morale of the teachers in this school is high; teachers work with enthusiasm; teachers take pride in this school; and, teachers value academic achievement. A standardized index (zero mean and unit standard deviation) was derived for principals' perceptions of teachers' morale and commitment.

Think university required for job. Dummy Variable. 1 if response to the question "How much education do you think is needed for this type of work? One university degree? or More than one university degree?" is "Yes"; o otherwise. Covers respondents who have decided what type of career of work they would be interested in having when they will be about 30 years old. This variable is available at age 15, 17 and 21(cycles 1, 2 and 4). 
Table A1

Summary Statistics

\begin{tabular}{|c|c|c|c|c|}
\hline & & & & \\
\hline & Mean & St. Dev. & Mean & St. Dev. \\
\hline PISA score $_{15}$ & $5 \cdot 510$ & 0.858 & 5.251 & 0.909 \\
\hline Think university required for job ${ }_{15}$ & 0.646 & 0.488 & 0.522 & 0.499 \\
\hline Think university required for job ${ }_{17}$ & 0.610 & 0.488 & 0.459 & 0.498 \\
\hline$\Delta$ Think university required for job ${ }_{17}$ & 0.425 & 0.784 & 0.272 & 0.757 \\
\hline Think university required for job ${ }_{21}$ & 0.609 & 0.488 & 0.490 & 0.500 \\
\hline Hours worked on $\mathrm{HW}_{15}$ & 3.763 & 3.336 & 2.917 & 3.038 \\
\hline Hours worked on $\mathrm{HW}_{17}$ & 6.311 & 4.170 & 4.929 & 3.923 \\
\hline$\Delta$ Hours worked on $\mathrm{HW}_{17}$ & 2.719 & 4.071 & 2.122 & 3.862 \\
\hline Percent females $_{15}$ & 0.419 & 0.493 & 0.368 & 0.482 \\
\hline Teacher quality $_{15}$ & 0.154 & 0.232 & 0.164 & 0.245 \\
\hline Government-independent private $_{15}$ & 0.013 & 0.111 & 0.019 & 0.138 \\
\hline Student-teacher ratio $_{15}$ & 16.838 & 2.806 & 16.883 & 2.900 \\
\hline Physical infrastructure shortage $_{15}$ & -0.113 & 0.802 & -0.138 & 0.772 \\
\hline Educational resource shortage $_{15}$ & 0.029 & 1.011 & -0.020 & 0.991 \\
\hline Teachers' morale and commitment $_{15}$ & 0.094 & 1.176 & 0.095 & 1.185 \\
\hline Parent(s) immigrant $_{15}$ & 0.093 & 0.291 & 0.093 & 0.289 \\
\hline Parental income $_{15}$ & 0.062 & 0.851 & 0.077 & 0.885 \\
\hline Non-birth parent $_{15}$ & 0.118 & 0.325 & 0.119 & 0.323 \\
\hline Father university $_{15}$ & 0.228 & 0.419 & 0.231 & 0.422 \\
\hline Mother university $_{15}$ & 0.193 & 0.394 & 0.205 & 0.404 \\
\hline Sibling drop-out ${ }_{15}$ & 0.069 & 0.255 & 0.056 & 0.229 \\
\hline Family educational support $_{15}$ & 0.076 & 0.869 & -0.125 & 0.937 \\
\hline Parents' nurturance behaviour ${ }_{15}$ & 0.066 & 0.982 & -0.069 & 1.025 \\
\hline Parental expectations $_{15}$ & 0.709 & 0.454 & 0.617 & 0.486 \\
\hline Friends smoke $_{15}$ & 0.973 & 0.841 & 0.878 & 0.819 \\
\hline Friends think it okay to work hard ${ }_{15}$ & 2.075 & 0.726 & 1.813 & 0.769 \\
\hline Friends think completing HS is important ${ }_{15}$ & 2.399 & 0.681 & 2.190 & 0.764 \\
\hline Friends think completing HS is important ${ }_{17}$ & 2.504 & 0.668 & 2.348 & 0.722 \\
\hline Friends think going to $\mathrm{PSE}_{15}$ & 2.197 & 0.704 & 1.966 & 0.754 \\
\hline Friends think going to $\mathrm{PSE}_{17}$ & 1.872 & 0.353 & 1.822 & 0.408 \\
\hline Grade-level average PISA ${ }_{15}$ & $4 \cdot 972$ & 0.511 & $4 \cdot 923$ & 0.593 \\
\hline High school GPA & 0.822 & 0.383 & 0.714 & 0.452 \\
\hline High school GPA & 0.846 & 0.361 & 0.723 & 0.447 \\
\hline High school GPA & 0.946 & 0.226 & 0.905 & 0.294 \\
\hline
\end{tabular}




\begin{tabular}{lcccc}
\hline & \multicolumn{2}{c}{$\mathrm{F}$} & \multicolumn{2}{c}{$\mathrm{M}$} \\
\cline { 2 - 5 } & Mean & St. Dev. & Mean & St. Dev. \\
\hline Aspirations to attend university $_{15}$ & 0.746 & 0.435 & 0.632 & 0.482 \\
Aspirations to attend university $_{17}$ & 0.704 & 0.456 & 0.609 & 0.488 \\
Aspirations to attend university $_{19}$ & 0.776 & 0.417 & 0.714 & 0.452 \\
Aspirations to attend university $_{21}$ & 0.738 & 0.439 & 0.659 & 0.474 \\
Attended university $_{19}$ & 0.709 & 0.454 & 0.621 & 0.485 \\
Attended university $_{21}$ & 0.711 & 0.453 & 0.608 & 0.488 \\
Attended university $_{23}$ & 0.736 & 0.441 & 0.646 & 0.478 \\
& & & & \\
Rural $_{15}$ & 0.439 & 0.496 & 0.416 & 0.493 \\
Atlantic provinces $_{15}$ & 0.392 & 0.488 & 0.369 & 0.483 \\
Manitoba, Saskatchewan $_{15}$ & 0.220 & 0.414 & 0.221 & 0.415 \\
Alberta $_{15}$ & 0.104 & 0.305 & 0.115 & 0.319 \\
British Columbia $_{15}$ & 0.103 & 0.305 & 0.112 & 0.315 \\
\hline
\end{tabular}

Note: "St. Dev." stands for standard deviation. 


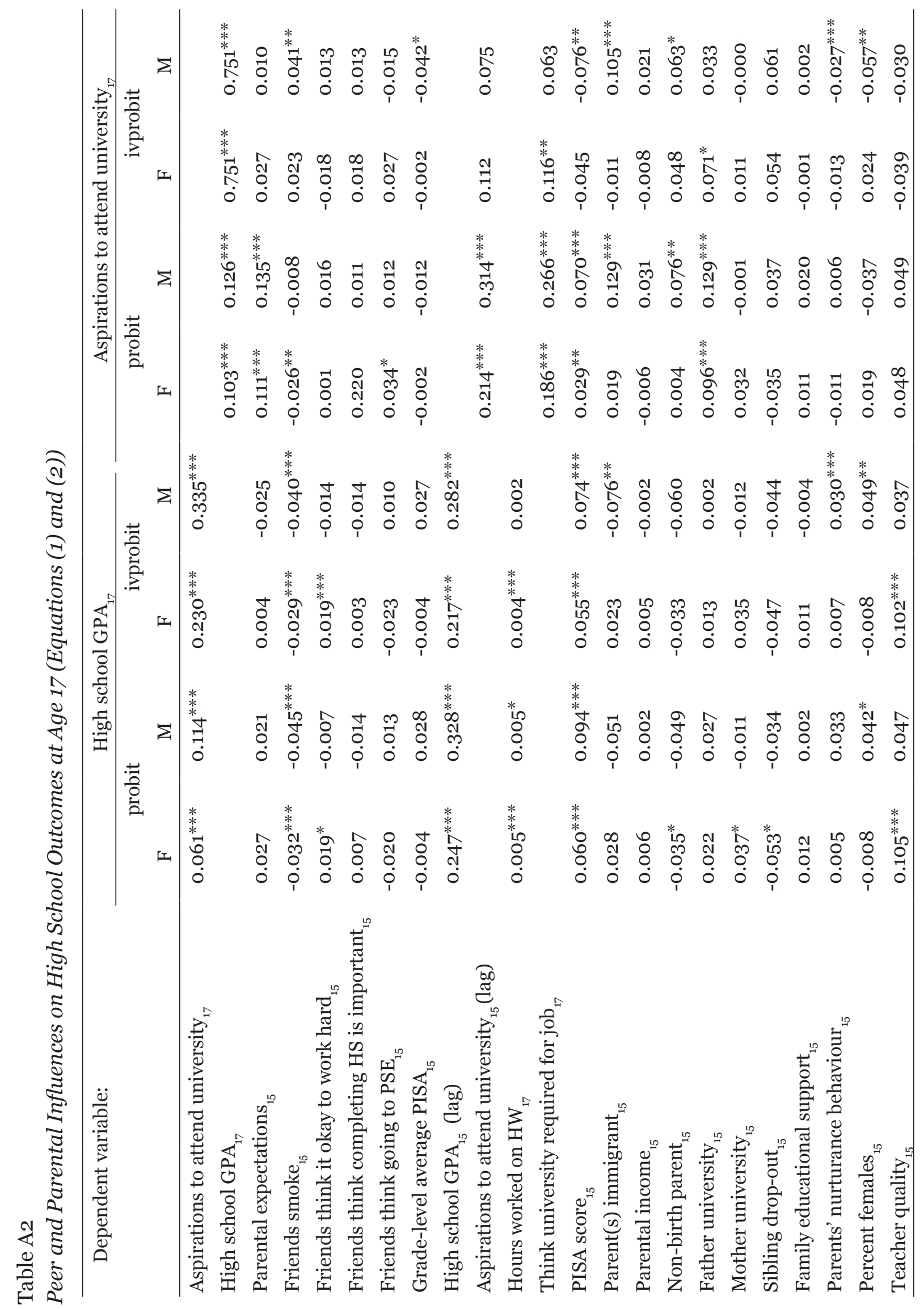




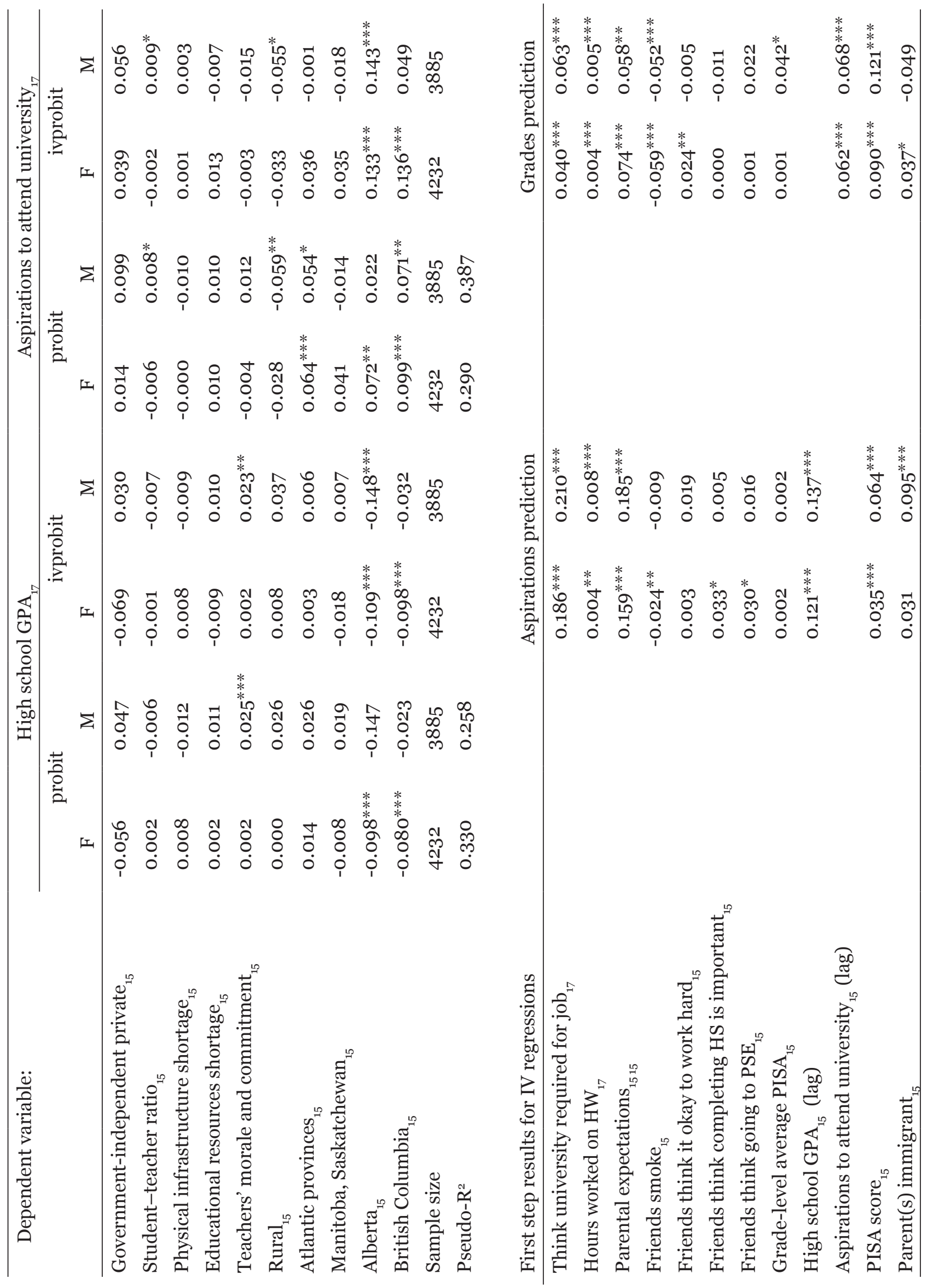




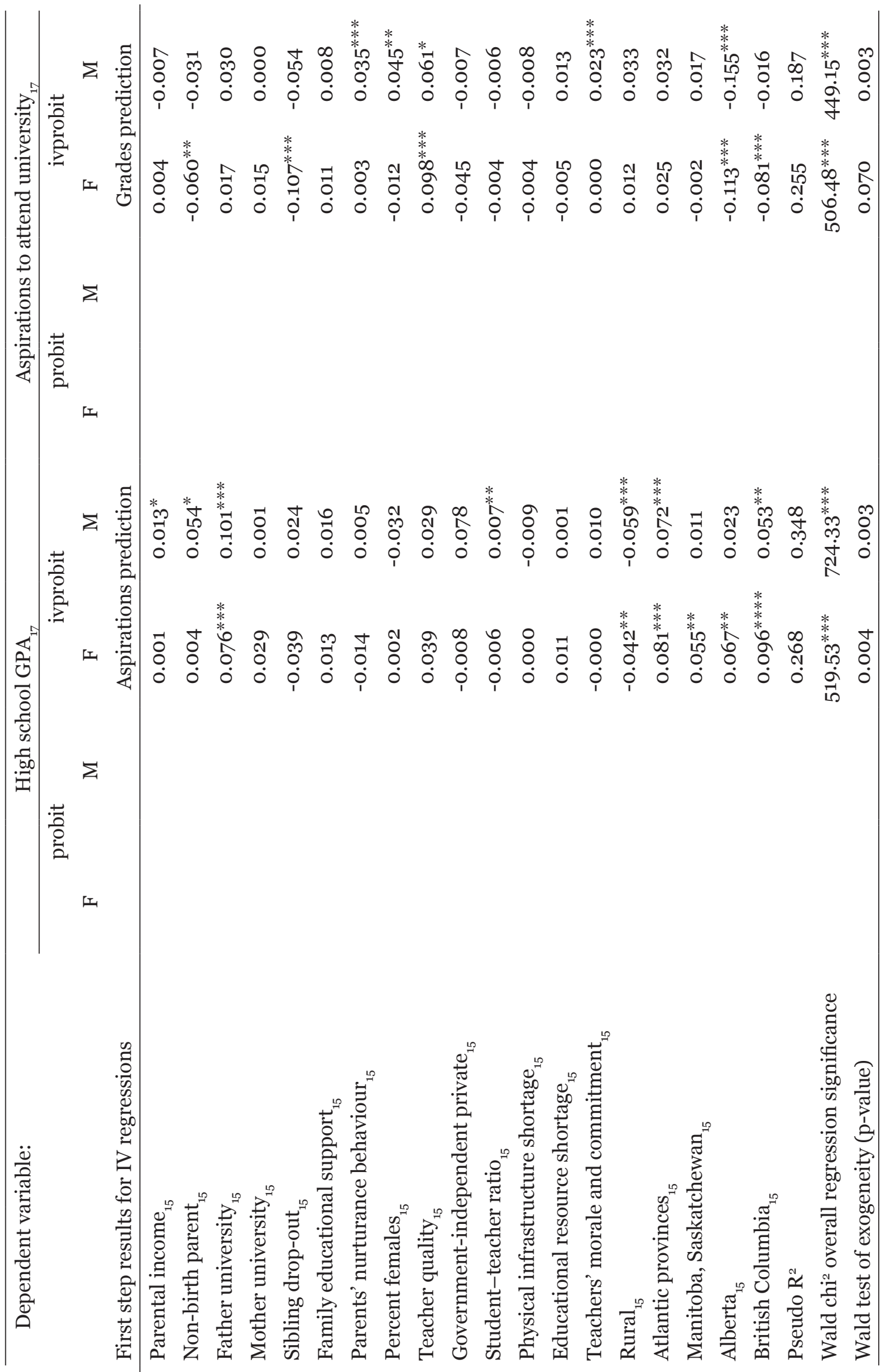




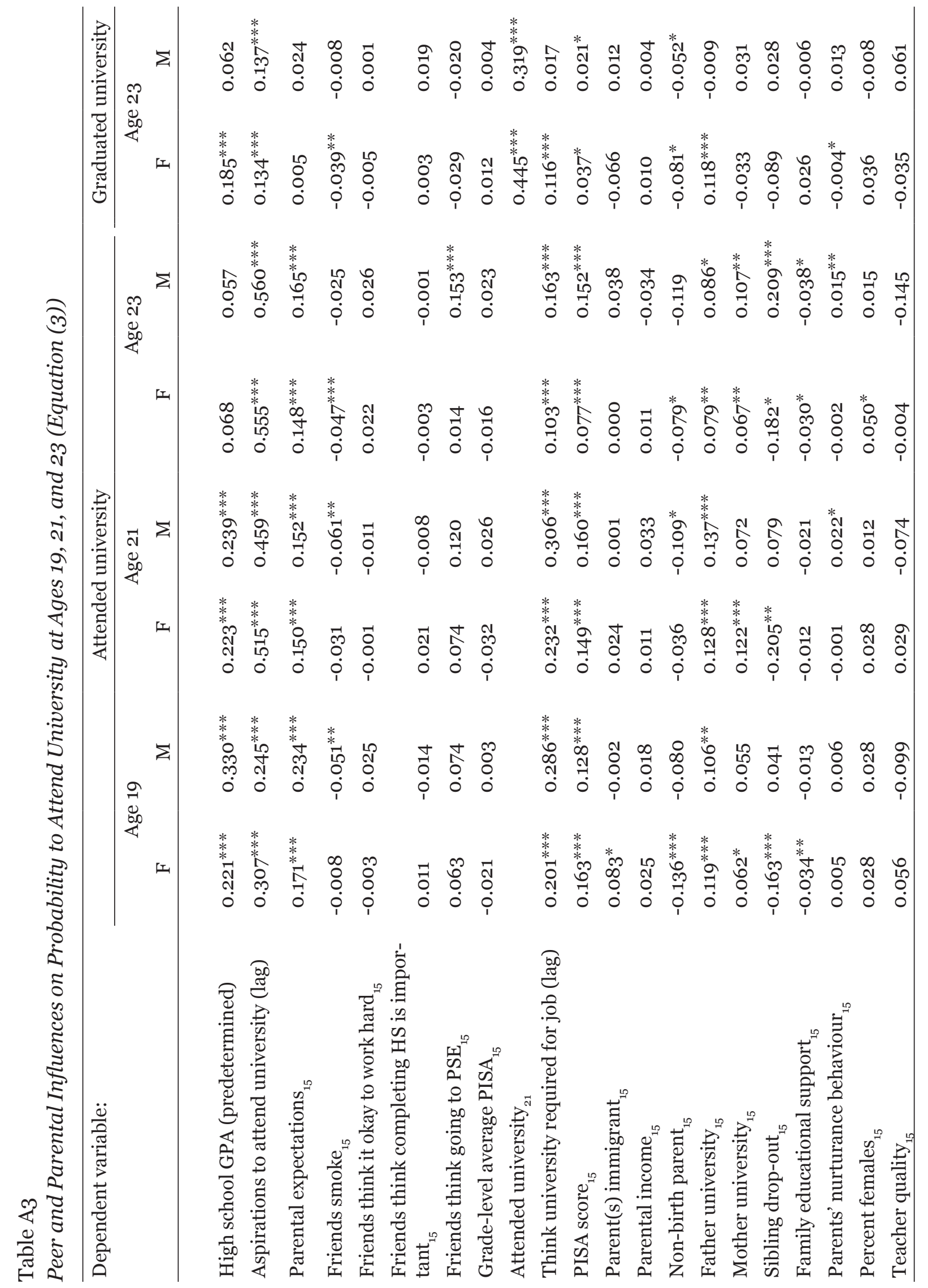




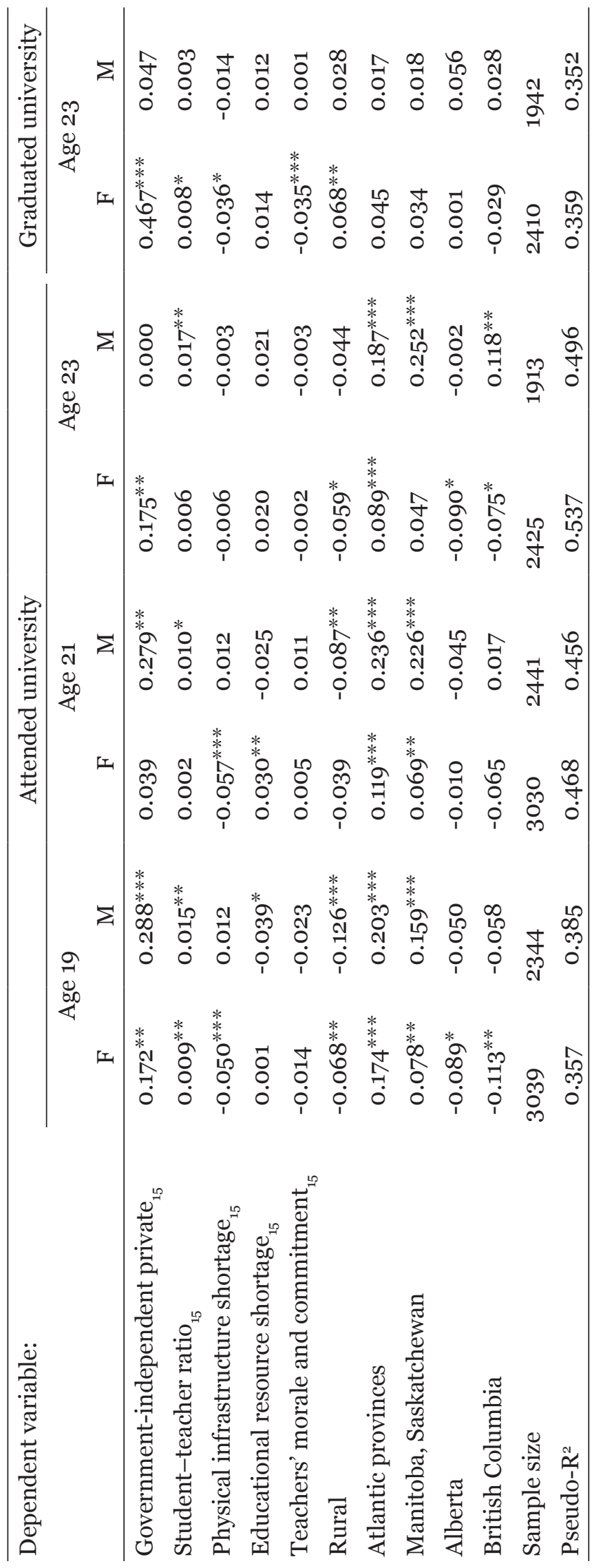


Table A4

Peer and Parental Influences on Probability to attend University (Equation (3)) at Age 19 by Position in the Parental Income Distribution

\begin{tabular}{|c|c|c|c|c|c|c|}
\hline \multirow{2}{*}{ Dependent variable: attended university ${ }_{19}$} & \multicolumn{2}{|c|}{ Lowest 25\% } & \multicolumn{2}{|c|}{ Middle 50\% } & \multicolumn{2}{|c|}{ Top 25\% } \\
\hline & $\mathrm{F}$ & M & $\mathrm{F}$ & M & $\mathrm{F}$ & M \\
\hline High school GPA ${ }_{17}$ & $0.275^{* *}$ & $0.424^{* * *}$ & $0.285^{* * *}$ & $0.381^{* * *}$ & 0.137 & $0.268^{* * *}$ \\
\hline Aspirations to attend university $_{17}$ & $0.352^{* * *}$ & $0.232^{* *}$ & $0.260^{* * *}$ & $0.206^{* * *}$ & $0.319^{* * * *}$ & $0.437^{* * *}$ \\
\hline Parental expectations $_{15}$ & $0.354^{* * *}$ & $0.157^{*}$ & $0.121^{* *}$ & $0.288^{* * *}$ & 0.063 & $0.191^{* *}$ \\
\hline Friends smoke $_{15}$ & 0.004 & -0.009 & 0.000 & $-0.123^{* * *}$ & -0.013 & 0.013 \\
\hline Friends think it okay to work hard ${ }_{15}$ & -0.017 & 0.015 & 0.018 & $0.061^{*}$ & 0.013 & 0.037 \\
\hline $\begin{array}{l}\text { Friends think completing HS is impor- } \\
\text { tant }_{15}\end{array}$ & 0.029 & 0.013 & 0.005 & -0.062 & -0.005 & 0.032 \\
\hline Friends think going to $\mathrm{PSE}_{15}$ & 0.053 & $0.188^{*}$ & 0.020 & 0.033 & $0.147^{*}$ & 0.003 \\
\hline Grade-level average PISA $_{15}$ & -0.060 & -0.048 & -0.021 & -0.029 & -0.049 & $0.116^{* *}$ \\
\hline Sample size & 781 & 565 & 1548 & 1172 & 732 & 627 \\
\hline Pseudo-R ${ }^{2}$ & 0.411 & 0.394 & 0.389 & 0.414 & 0.364 & 0.457 \\
\hline Mean Y & 0.602 & 0.534 & 0.665 & 0.569 & 0.773 & 0.686 \\
\hline Gender gap & \multicolumn{2}{|c|}{0.068} & \multicolumn{2}{|c|}{0.096} & \multicolumn{2}{|c|}{0.087} \\
\hline
\end{tabular}

Note: Significance levels: $0.01^{* * *}, 0.05^{* *}, 0.10^{*}$. The table presents probit marginal effects evaluated at the mean. The specification is the same as in Table A3. 
Table A5

Peer and Parental Influences on Probability to Attend University (Equation (3)) at Age 21 by Position in the Parental Income Distribution

\begin{tabular}{|c|c|c|c|c|c|c|}
\hline \multirow{2}{*}{$\begin{array}{l}\text { Dependent variable: attended } \\
\text { university }_{21}\end{array}$} & \multicolumn{2}{|c|}{ Lowest $25 \%$} & \multicolumn{2}{|c|}{ Middle 50\% } & \multicolumn{2}{|c|}{ Top 25\% } \\
\hline & $\mathrm{F}$ & M & $\mathrm{F}$ & M & $\mathrm{F}$ & M \\
\hline High school GPA & 0.148 & 0.089 & $0.337^{* * *}$ & $0.330^{* * *}$ & 0.152 & $0.220^{* *}$ \\
\hline $\begin{array}{l}\text { Aspirations to attend univer- } \\
\text { sity }_{19}\end{array}$ & $0.626^{* * *}$ & $0.489 * * *$ & $0.509^{* * *}$ & $0.481^{* * * *}$ & $0.484^{* * *}$ & $0.504^{* * *}$ \\
\hline Parental expectations $_{15}$ & $0.284^{* * *}$ & 0.129 & $0.138^{* * *}$ & $0.198^{* * *}$ & 0.084 & 0.058 \\
\hline Friends smoke $_{15}$ & 0.003 & -0.075 & -0.029 & -0.055 & $-0.046^{*}$ & $-0.077^{* *}$ \\
\hline $\begin{array}{l}\text { Friends think it okay to work } \\
\text { hard }_{15}\end{array}$ & -0.067 & -0.079 & 0.042 & 0.019 & 0.002 & -0.022 \\
\hline $\begin{array}{l}\text { Friends think completing HS } \\
\text { is important } \\
{ }_{15}\end{array}$ & $0.077^{*}$ & 0.039 & -0.005 & $-0.076^{*}$ & 0.001 & $0.092^{*}$ \\
\hline Friends think going to $\mathrm{PSE}_{15}$ & $0.161^{*}$ & $0.201^{*}$ & -0.012 & 0.112 & 0.121 & 0.063 \\
\hline${\text { Grade-level average } \text { PISA }_{15}}$ & -0.094 & 0.110 & -0.069 & -0.017 & 0.021 & 0.063 \\
\hline Sample size & 791 & 571 & 1536 & 1234 & 726 & 648 \\
\hline Pseudo-R ${ }^{2}$ & 0.481 & 0.497 & 0.488 & 0.466 & 0.503 & 0.504 \\
\hline Mean Y & 0.627 & 0.507 & 0.689 & 0.537 & 0.740 & 0.654 \\
\hline Gender gap & \multicolumn{2}{|c|}{0.120} & \multicolumn{2}{|c|}{0.152} & \multicolumn{2}{|c|}{0.086} \\
\hline
\end{tabular}

Note: Significance levels: $0.01^{* * *}, 0.05^{* *}, 0.10^{*}$. The table presents probit marginal effects evaluated at the mean. The specification is the same as in Table A3. 